\title{
Plantar forefoot pressures in psoriatic arthritis-related dactylitis: an exploratory study
}

\author{
Richard A. Wilkins $^{1,2} \cdot$ Heidi J. Siddle ${ }^{1,2}$ • Anthony C. Redmond ${ }^{1} \cdot$ Philip S. Helliwell ${ }^{1,3}$
}

Received: 11 December 2015 /Revised: 4 May 2016 / Accepted: 7 May 2016 / Published online: 26 May 2016

(C) The Author(s) 2016. This article is published with open access at Springerlink.com

\begin{abstract}
Dactylitis is a common feature of psoriatic arthritis (PsA); local physical trauma has been identified as a possible contributing factor. The aim of this study was to explore differences in forefoot plantar pressures in patients with PsA with and without dactylitis and compare to healthy controls. Thirtysix participants were recruited into three groups: group A PsA plus a history of dactylitis; group B PsA, no dactylitis; group $\mathrm{C}$ control participants. Forefoot plantar pressures were measured barefoot and in-shoe at the left second and fourth toes and corresponding metatarsophalangeal joints. Temporal and spatial parameters were measured and data from the foot impact scale for rheumatoid arthritis (FIS-RA), EQ5D and health assessment questionnaire (HAQ) were collected. Pressure time integral peak plantar pressure, and contact time barefoot and in-shoe were not significantly different between groups. Temporal and spatial parameters reported no significant differences between groups. ANOVA analysis and subsequent post hoc testing using Games-Howell test yielded significance in FIS-RA scores between both PsA groups versus controls, A $p \leq 0.0001$ and PsA group B $p<0.0001$ in the FIS-RA impairment and footwear domain, PsA group A $p<0.03$ and PsA group $\mathrm{B} p \leq 0.05$ in the FIS-RA activity and participation
\end{abstract}

Richard A. Wilkins

r.a.wilkins@leeds.ac.uk

1 Section of Clinical Biomechanics and Physical Medicine, Leeds Institute of Rheumatic and Musculoskeletal Medicine, 2nd Floor, Chapel Allerton Hospital, Chapeltown Road, Leeds LS7 4SA, UK

2 Foot Health Department, Leeds Teaching Hospitals NHS Trust, Lower Ground Floor, Chancellor Wing, St James's University Hospital, Beckett Street, Leeds LS9 7TF, UK

3 Rheumatology Department, Bradford Teaching Hospitals NHS foundation Trust, St Luke's Hospital, Little Horton Lane, Bradford BD5 0NA, UK domain compared to controls. This is the first exploratory study to investigate forefoot plantar pressures in patients with and without historical dactylitis in PsA. FIS-RA scores indicate PsA patients have significant limitations compared to controls, although a history of dactylitis does not appear to worsen patient reported outcomes.

Keywords Dactylitis · Plantar pressure measurement · Psoriatic arthritis · Toe

\section{Introduction}

Levels of peripheral joint damage are lower in psoriatic arthritis (PsA) compared to rheumatoid arthritis (RA), although foot impairment and disability are reported in two thirds of patients particularly at the forefoot [1]. Patients report a reduction in quality of life, with limitations in function and disability described as equivalent to that of RA. Despite lower levels of peripheral joint damage however the effect on patients reported pain and disability are significant [2,3]. Dactylitis is one of the most common features of PsA occurring in around $40 \%$ of cases. It is classed as a hallmark feature of the disease and forms part of the classification criteria for PsA [4]. Dactylitis, also referred to as sausage digit presents clinically as an acute painful inflammation of the digit which in the chronic phase can remain swollen following the subsidence of acute inflammation.

Magnetic resonance imaging (MRI) studies have identified dactylitis as a polyarticular disease process, with multiple pathologies and varying levels of severity. Bone oedema and flexor tenosynovitis have been observed and, to a lesser degree, extensor tenosynovitis. Furthermore, synovitis and soft tissue oedema occur in tender and non-tender dactylitis [5]. Trauma has been suggested as a potential trigger for PsA and 


\section{Distribution of toe dactylitis}

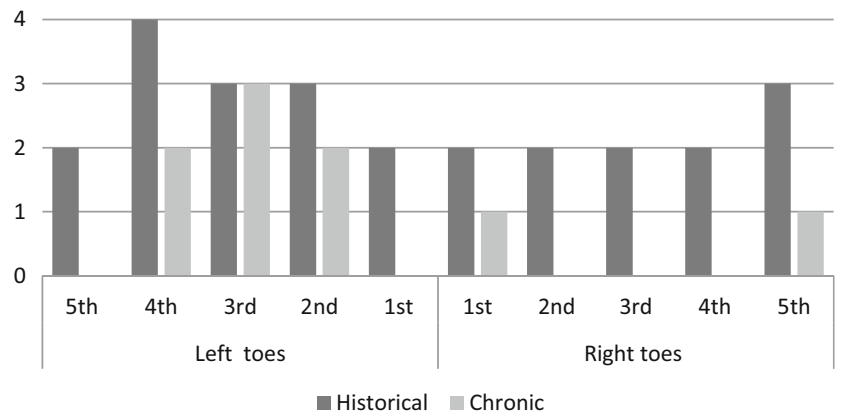

Fig. 1 Distribution of current (chronic) and historical dactylitis in both feet

direct physical injury may influence peripheral manifestations such as dactylitis and enthesitis. Furthermore, high levels of stress at entheses are suggested as a biomechanical trigger to enthesitis and the other manifestations of the disease [6].

It has been hypothesised that dactylitis in the hand may be caused by mechanical trauma to distal phalangeal and metacarpal joints. This is thought to result in an inflammatory response at the digit, known as the 'deep Koebner' phenomenon $[4,7,8]$. Toe dactylitis is more common than finger dactylitis which may support the mechanical pathogenesis hypothesis given the load bearing function of the toes, but there are no investigations to support a mechanical trigger [7, 8]. It has also been suggested that psoriatic nail disease may be linked to micro trauma occurring within the nail bed [9].

Pain at the forefoot has been reported in RA to reduce the ambulatory performance in the presence of foot deformity and pain. Localised foot pain may lead to altered changes in temporal and spatial parameters of gait leading to altered gait patterns and functional adaption [10, 11]. During normal walking, the toes function to increase the total weight-bearing area of the forefoot and disperse the mechanical load from the metatarsal-phalangeal (MTP) joints [12]. At the propulsive phase of gait where forefoot forces are highest, muscle activation occurs to facilitate propulsion. Force generated at the forefoot and musculature is increased, which in inflammatory diseases such as PsA maybe abnormal leading to changes in plantar pressures $[12,13]$. Although the role of plantar MTP joint pressure distributions have been investigated in PsA, no study has investigated toe dactylitis [14]. In other systemic conditions, such as RA and diabetes, increases in
Table 1 Demographics, disease variables and patient reported outcome measures

\begin{tabular}{|c|c|c|c|}
\hline & \multicolumn{3}{|l|}{ Group } \\
\hline & $\begin{array}{l}\text { PsA dactylitis } \\
\text { (group A) }\end{array}$ & $\begin{array}{l}\text { PsA no history of dactylitis } \\
\text { (group B) }\end{array}$ & $\begin{array}{l}\text { Normal } \\
\text { (group C) }\end{array}$ \\
\hline \multicolumn{4}{|l|}{ Demographics (SD) (range) } \\
\hline Gender M:F & $11: 1$ & $4: 8$ & $7: 5$ \\
\hline Age, mean & $36.7(21.5)(25-58)$ & $45.3(16.2)(20-81)$ & $39.7(8.8)(29-58)$ \\
\hline Disease duration (y) & $4.6(6.7)(1-25)$ & $4.6(5.6)(1-20)$ & $0(0)$ \\
\hline Weight $(\mathrm{kg})$ & $90.9(21.5)(54-133)$ & $81.3(29.8)(51-162)$ & $71.8(15)(48-98)$ \\
\hline Height (m) & $1.8(0.1)(1.6-1.9)$ & $1.7(0.1)(1.5-1.9)$ & $1.7(0.1)(1.8-1.9)$ \\
\hline \multicolumn{4}{|l|}{ Medication (n) } \\
\hline DMARDs & 10 & 11 & 0 \\
\hline Biologics & 7 & 6 & 0 \\
\hline \multicolumn{4}{|l|}{ FIS-RA (SD) (range) } \\
\hline \multicolumn{4}{|l|}{ FIS-RA (SD) (range) } \\
\hline FIS-RA $A_{I F}$ & $7.16(5.78)(0-15)$ & $6.83(4.19)(0-12)$ & $0.41(0.79)(0-2)$ \\
\hline $95 \%$ CI lower bound & 3.49 & 4.16 & -0.08 \\
\hline $95 \%$ CI upper bound & 10.84 & 9.49 & 0.92 \\
\hline FIS-RA $A_{\mathrm{AP}}$ & $8.75(10.22)(0-25)$ & $5.75(7.30)(0-22)$ & $0.16(0.38)(0-1)$ \\
\hline $95 \%$ CI lower bound & 2.25 & 1.11 & -0.08 \\
\hline $95 \%$ CI upper bound & 15.24 & 10.38 & 0.41 \\
\hline \multicolumn{4}{|l|}{ EQ-5D } \\
\hline Mobility & $1.42(0.51)$ & $1.50(0.52)$ & $1.0(0)$ \\
\hline Self-care & $1.25(0.45)$ & $1.08(0.28)$ & $1.0(0)$ \\
\hline Activity & $1.50(0.67)$ & $1.50(0.52)$ & $1.08(0.28)$ \\
\hline Pain & $1.67(0.49)$ & $1.67(0.49)$ & $1.17(0.38)$ \\
\hline Anxiety & $1.25(0.45)$ & $1.33(0.49)$ & $1.00(0)$ \\
\hline VAS & $66.67(23.17)$ & $78.33(14.63)$ & $89.78(9.9)$ \\
\hline HAQ & $0.45(0.84)$ & $0.30(0.41)$ & $0.03(0.10)$ \\
\hline
\end{tabular}


Table 2 Post hoc test Games-Howell FIS-RA subscales

Groups

\begin{tabular}{|c|c|c|c|c|c|}
\hline \multicolumn{2}{|l|}{$\begin{array}{l}\text { PsA dactylitis } \\
\text { (group A) } \\
\text { (1) }\end{array}$} & \multicolumn{2}{|c|}{$\begin{array}{l}\text { PsA no history of dactylitis } \\
\text { (group B) } \\
\text { (1) }\end{array}$} & \multicolumn{2}{|l|}{$\begin{array}{l}\text { Normal } \\
\text { (group C) } \\
(1)\end{array}$} \\
\hline $\begin{array}{l}\text { PsA no history of dactylitis } \\
\text { (group B) } \\
\text { (2) }\end{array}$ & $\begin{array}{l}\text { Normal } \\
\text { (group C) } \\
(2)\end{array}$ & $\begin{array}{l}\text { PsA dactylitis } \\
\text { (group A) } \\
\text { (2) }\end{array}$ & $\begin{array}{l}\text { Normal } \\
\text { (group C) } \\
(2)\end{array}$ & $\begin{array}{l}\text { PsA dactylitis } \\
\text { (group A) } \\
(2)\end{array}$ & $\begin{array}{l}\text { PsA no history of dactylitis } \\
\text { (group B) } \\
\text { (2) }\end{array}$ \\
\hline 0.33 & 6.75 & -0.33 & 1.23 & 1.68 & 1.23 \\
\hline 0.986 & 0.00 & 0.986 & 0.00 & 0.00 & 0.00 \\
\hline-4.88 & 2.28 & -5.54 & 3.11 & -11.27 & -9.71 \\
\hline 5.54 & 11.27 & 4.88 & 9.71 & -2.22 & -3.11 \\
\hline 3.00 & 8.58 & -3.00 & 5.58 & -8.58 & -5.58 \\
\hline 0.691 & 0.03 & 0.69 & 0.05 & 0.03 & 0.05 \\
\hline-6.179 & 0.60 & -12.17 & -0.11 & -16.55 & -11.27 \\
\hline 12.17 & 16.55 & 6.17 & 11.27 & -0.60 & 0.11 \\
\hline
\end{tabular}

pressure and the time over which pressure occurs have been linked to mechanical tissue damage and ulceration $[10,15,16]$. To the authors' knowledge, no study has investigated the effect of toe dactylitis.

It is therefore the aim of this exploratory study to investigate variations in plantar pressures at the most commonly reported sites of dactylitis and their corresponding MTP joints in patients with a history of dactylitis when compared to controls (PsA, no history of dactylitis) and normal participants.

\section{Method}

Ethical approval was obtained from the NRES Committee Yorkshire and Humber-Leeds East. Written informed consent was obtained from all participants.

The study was cross-sectional in design with 36 participants recruited as a convenience sample of consecutive patients identified by two consultant rheumatologists. Twelve participants with PsA and a previous history of dactylitis/chronic dactylitis (group A) and 12 participants with PsA but no previous history of dactylitis (group B) were recruited from the rheumatology outpatient department, Chapel Allerton Hospital, Leeds Teaching Hospitals NHS Trust. A control group of 12 heathy participants were also recruited (group C). These control participants did not report any musculoskeletal or rheumatological disease and had no current or medical history of foot and ankle pain. Control participants were age $(+/-2$ years) and gender matched. Disease duration (years) was recorded for all patients with PsA. The sites of historical dactylitis (digit number, left/ right) were recorded for all PsA patients in group A.
The EQ-5D was used to capture participant health status and self-rated health. The health assessment questionnaire (HAQ) was also used and provided a measure of the patient's health, functional status, symptoms, and quality of life from the participants' own perspective. Both EQ-5D and HAQ have been reported in PsA previously (ref). The foot impact scale for rheumatoid arthritis (FIS-RA) was used to measure the impact of foot pathology on impairment and footwear (FIS-RA $A_{I F}$ ), and activity limitation and participation restriction (FIS-RA ${ }_{\mathrm{AP}}$ ) [17]. Although the FIS-RA is not specific to PsA it has been used previously [2].

Temporal and spatial parameters of walking were collected using the GAITRite system, a 10-metre instrumented walkway. Barefoot plantar pressure measurement and dynamic foot/shoe interface pressures were collected using the novel eMED SF and Pedar in-shoe systems (Novel GmbH, Munich, Germany), respectively. Peak plantar pressure $(\mathrm{PPP})(\mathrm{kPa})$, contact area $(\mathrm{CA})$ $\left(\mathrm{cm}^{2}\right)$ and pressure time integral $(\mathrm{PTI})(\mathrm{kPa} / \mathrm{s})$ were analysed at the most common (fourth toe) and second most common (second toe) sites of dactylitis and corresponding metatarsophalangeal (MTP) joints. Three representative steps were collected for barefoot pressures using a common two-step start protocol [18, 19]. Dynamic in-shoe pressure was collected by inserting a flexible pressure measuring insole into the participant's footwear. The participant undertook two straight line walks of an 8-m walkway generating 20 representative steps [19].

\section{Data analysis}

A sample size of 36 was used (12 participants per group), based on a rationale including feasibility, precision about the 
mean and variance and regulatory considerations for sample size calculations [20]. The most symptomatic foot (left) in group A (PsA dactylitis) was selected for analysis (Fig. 1). IBM Statistical package for Social Sciences (SPSS) Version 19 for Windows 7 was used to analyse data. Descriptive statistics were used to report patient demographics, betweengroup spatial and temporal parameters (gait velocity $(\mathrm{m} / \mathrm{s})$, cadence (steps/min) and period of double support (\%)). Between-group differences were explored using a one-way analysis of variance (ANOVA) for PPP $(\mathrm{kPa})$, PTI $(\mathrm{kPa} / \mathrm{s})$ and the FIS-RA. A subsequent Games-Howell post hoc test explored differences between paired combinations of the three groups (A and B, B and C, C and A). A $p$ value of $\leq 0.05$ was chosen to detect the probability.

\section{Results}

Thirty-six participants were analysed for this exploratory study. Patient demographics, patient-reported outcome measures and temporal and spatial data are presented descriptively in Table 1.

Descriptive of HAQ and EQ-5D are reported in Table 1. There were no significant differences between groups. In the
FIS-RA a mean FIS-RA ${ }_{\text {IF }}$ score of 7.16 in group $A$ and 6.83 in group $\mathrm{B}$ compared to 0.41 in the control group, and a mean FIS-RA ${ }_{\mathrm{AP}}$ score of 8.75 in group $\mathrm{A}$ and 5.75 in group $\mathrm{B}$ compared to 0.16 in the control group; ANOVA analysis and subsequent post-hoc testing identified statistically significance differences between groups in FIS-RA scores (Table 2). In both domains of the FIS-RA, there was a significant difference between both PsA groups compared to the control group; PsA group A $p=0.0001$ and PsA group $\mathrm{B} p=0.0001$ in the FIS$\mathrm{RA}_{\mathrm{IF}}$ domain, PsA group A $p=0.03$ and PsA group $\mathrm{B} p=0.05$ in the FIS-RA $A_{\mathrm{AP}}$ domain.

Descriptive statistics of mean plantar pressure variables (PPP, PTI, CA) are reported in Table 3. ANOVA analysis of measurements barefoot and in-shoe (Table 4) indicated no significant differences between groups. No significant differences were reported in spatial and temporal parameters of gait between groups (Table 1).

\section{Discussion}

This is the first study to explore the mechanical factors that may contribute to toe dactylitis in patients with PsA and to examine the impact of dactylitis on foot pain and disability.

Table 3 Gait and plantar pressure descriptive statistics

\begin{tabular}{|c|c|c|c|}
\hline \multicolumn{4}{|l|}{ Temporal and spatial (SD) (range) } \\
\hline Velocity $(\mathrm{m} / \mathrm{s})$ & $1.23(0.17)(0.59-1.44)$ & $1.23(0.24)(0.59-1.44)$ & $1.47(0.14)(1.28-1.75)$ \\
\hline Cadence & $116.8(7.34)(103-125)$ & $120.03(9.26)(105-138)$ & $120.26(5.57)(110-128)$ \\
\hline Double support (\% of gait cycle left) & $22.56(3.17)(17-28)$ & $23.67(4.40)(19-33)$ & $19.55(2.31)(15-22)$ \\
\hline Double support ( $\%$ of gait cycle right) & $22.61(3.19)(18-28)$ & $23.40(4.42)(20-33)$ & $19.27(2.36)(15-22)$ \\
\hline \multicolumn{4}{|l|}{ PP/PTI/CA Emed-SF (SD) (range) } \\
\hline PP left 2nd toe & $296.6(238)(62-952)$ & $197.3(97.3)(0-317)$ & $245.6(128.8)(68-455)$ \\
\hline PP left 4th toe & $88.2(55.8)(15-232)$ & $81.4(90.2)(0-292)$ & $122.7(82.9)(10-272)$ \\
\hline PP left 2nd MTP joint & $555.3(260.3)(110-1035)$ & $601.8(242.8)(268-1047)$ & $633.6(305.5)(353-1235)$ \\
\hline PP left 4th MTP joint & $372.8(203.8)(75-753)$ & $330.4(128.7)(208-698)$ & 314.5 (104) (170-492) \\
\hline PTI left 2nd toe & $64.3(54.2)(18-211)$ & $38.9(21.1)(0-64)$ & $51.2(37.8)(13-158)$ \\
\hline PTI left 4th toe & $19.5(13.2)(1-50)$ & $19.3(24.9)(0-83)$ & $28.5(20.8)(1-64)$ \\
\hline PTI left 2nd MTP joint & $162.4(64.4)(17-259)$ & $188(88.3)(66-330)$ & $167.3(62.3)(92-288)$ \\
\hline PTI left 4th MTP joint & $135.3(74.9)(24-267)$ & $110.4(38.7)(76-212)$ & $100.8(33.9)(58-181)$ \\
\hline Contact area left 2 nd toe & $3.78(.50)(0-2)$ & $3.39(1.34)$ & $3.70(.93)$ \\
\hline Contact area left 4 th toe & $2.52(.88)$ & $1.96(1.52)$ & $2.68(.92)$ \\
\hline Contact area left 2nd MTP joint & $9.82(1.43)$ & $9.90(1.81)$ & $9.70(1.14)$ \\
\hline Contact area left 4th MTP joint & $9.11(1.86)$ & $8.89(1.49)$ & $8.87(1.30)$ \\
\hline \multicolumn{4}{|l|}{ PP/ PTI/CA PEDAR (SD) (range) } \\
\hline PP left lesser toes & $117.9(45.1)(54-194)$ & $110(42.2)(24-162)$ & $108.7(43.6)(64-228)$ \\
\hline PP Left MTP joints & $301.9(68.2)(165-454)$ & $271.4(100.8)(164-482)$ & $300.7(71.8)(215-455)$ \\
\hline PTI left lesser toes & $301.9(68.2)(165-454)$ & $271.4(100.8)(164-482)$ & $300.7(71.8)(215-455)$ \\
\hline PTI left MTP joints & $84.12(35.2)(54-167)$ & $74.5(30.9)(37-128)$ & $68.32(14.6)(45-96)$ \\
\hline CA left lesser toes & $8.1(1.1)(3.7)$ & $6.6(2.5)(10.3)$ & $7.4(0.9)(2.9)$ \\
\hline CA left MTP joints & $18.4(2.9)(11.5)$ & $15.5(5.3)(21.3)$ & $17.4(3.3)(10.6)$ \\
\hline
\end{tabular}


Table 4 ANOVA one-way analysis of emed-SF barefoot and PEDAR in-shoe data contact area (CA), peak plantar pressures (PPP) and pressure time integral (PTI)

\begin{tabular}{|c|c|c|c|}
\hline & & Mean square & Sig. \\
\hline \multirow[t]{2}{*}{ PPP left 2nd toe } & Between groups & 5035.533 & 0.43 \\
\hline & Within groups & 5961.038 & \\
\hline \multirow[t]{2}{*}{ PPP left 4th toe } & Between groups & 15499.007 & 0.48 \\
\hline & Within groups & 21111.535 & \\
\hline \multirow[t]{2}{*}{ PPP left 2nd MTP joint } & Between groups & 17317.560 & 0.78 \\
\hline & Within groups & 69591.536 & \\
\hline \multirow[t]{2}{*}{ PPP left 4th MTP joint } & Between groups & 37784.462 & 0.27 \\
\hline & Within groups & 27993.069 & \\
\hline \multirow[t]{2}{*}{ PTI left 2nd toe } & Between groups & 37784.462 & 0.27 \\
\hline & Within groups & 27993.069 & \\
\hline \multirow[t]{2}{*}{ PTI left 4th toe } & Between groups & 37784.462 & 0.27 \\
\hline & Within groups & 27993.069 & \\
\hline \multirow[t]{2}{*}{ PTI left 2nd MTP joint } & Between groups & 37784.462 & 0.27 \\
\hline & Within groups & 27993.069 & \\
\hline \multirow[t]{2}{*}{ PTI left 4th MTP joint } & Between groups & 37784.462 & 0.27 \\
\hline & Within groups & 27993.069 & \\
\hline \multirow[t]{2}{*}{ CA left 2nd toe } & Between groups & 0.936 & 0.40 \\
\hline & Within groups & 0.986 & \\
\hline \multirow[t]{2}{*}{ CA left 4th toe } & Between groups & 1.719 & 0.28 \\
\hline & Within groups & 1.315 & \\
\hline \multirow[t]{2}{*}{ CA left 2nd MTP joint } & Between groups & 0.123 & 0.85 \\
\hline & Within groups & 2.228 & \\
\hline \multirow[t]{2}{*}{ CA left 4th MTP joint } & Between groups & 0.225 & 0.91 \\
\hline & Within groups & 2.475 & \\
\hline \multirow[t]{2}{*}{ PEDAR PPP left toes } & Between groups & 291.323 & 0.85 \\
\hline & Within groups & 1908.989 & \\
\hline \multirow[t]{2}{*}{ PEDAR PPP left MTP joints } & Between groups & 3369.648 & 0.60 \\
\hline & Within groups & 6543.641 & \\
\hline \multirow[t]{2}{*}{ PEDAR PTI left toes } & Between groups & 23.181 & 0.81 \\
\hline & Within groups & 112.885 & \\
\hline \multirow[t]{2}{*}{ PEDAR PTI left MTP joints } & Between groups & 759.532 & 0.39 \\
\hline & Within groups & 797.616 & \\
\hline \multirow[t]{2}{*}{ PEDAR CA left MTP toes } & Between groups & 6.483 & 0.11 \\
\hline & Within groups & 2.697 & \\
\hline \multirow[t]{2}{*}{ PEDAR CA left MTP joints } & Between groups & 24.984 & 0.22 \\
\hline & Within groups & 15.485 & \\
\hline
\end{tabular}

Patients with PsA, with and without dactylitis, reported worse impairment, footwear, activity limitation and participant restriction when compared to a control group of normal participants. Analysis of peak plantar pressure, pressure time integral and contact area at the 2nd and 4th toes, and 2nd and 4th MTP joints of the left foot found no significant differences between groups. Descriptive analysis of temporal and spatial parameters of gait identified no differences between any of the three groups (A, B, C). Having a history of dactylitis did not have a significant effect on plantar pressure measurement and patient-reported foot impact in patients with PsA.
This study in PsA has provided an insight in to the mechanical factors that may be associated with toe dactylitis and aided the formation of a hypothesis for a future study. Although differences in PsA PPP, PTI and contact area were not identified, the results indicate that pressure may not be as relevant to the cause of trauma as previously hypothesised. In other diseases, such as RA, inflammatory changes at the forefoot leads to altered joint mechanics and increased plantar pressures [10]. This was not the finding of this study and supports the research carried out by Turner et al. who reported plantar pressures at the MTP joint did not correlate to joint damage and pain in patients with PsA [14]. Active or historical dactylitis did not correlate with changes in plantar pressures. Investigating the effect of dorsal and plantar shear force on the forefoot structures in the future may provide more insight into mechanical properties of soft tissue.

\section{Limitations}

The authors acknowledge several limitations to this study. Whilst a sample size of 12 per group is accepted in an exploratory study the inability to adequately power may increase the risk of error. A power calculation using the new data indicates that 60 participants per group would be needed to demonstrate a significant difference between groups if these results were found. Capturing details of disease activity may have provided more insight into the condition and the patient disease status at the point of data collection such as active systemic inflammation which may affect the patient's ability to weight bear through the forefoot. Including both chronic and historical dactylitis may have affected results. The inclusion of historical dactylitis in group A may have negatively impacted on the results and lessened the impact that current dactylitis may have had on gait parameter and altered function. Details of foot deformity, foot posture and footwear characteristics may also provide insight into plantar pressure data reported and contributing factors such as foot type, poor fitting footwear or poor mechanical properties.

\section{Conclusion}

In conclusion, the main finding of this exploratory study is that patient-reported functional limitation and disability in PsA is significant, regardless of whether or not there is a history of dactylitis. Further research is necessary in larger patient numbers using more sophisticated measures, and capturing variables of foot type, foot deformity and footwear in conjunction with disease activity scores to determine whether 
variations in plantar pressures contribute to the manifestation of dactylitis in the toes of patients with PsA.

Open Access This article is distributed under the terms of the Creative Commons Attribution 4.0 International License (http:// creativecommons.org/licenses/by/4.0/), which permits unrestricted use, distribution, and reproduction in any medium, provided you give appropriate credit to the original author(s) and the source, provide a link to the Creative Commons license, and indicate if changes were made.

\section{References}

1. Hyslop E, Turner DE, McInnes IB, Woodburn J (2008) An outpatient survey of foot problems in psoriatic arthritis (PSA). Paper presented at the EULAR, Paris

2. Hyslop E, McInnes IB, Woodburn J, Turner DE (2010) Foot problems in psoriatic arthritis: high burden and low care provision. Ann Rheum Dis 69(5):928. doi:10.1136/ard.2009.111971

3. Boehncke W-H, Menter A (2013) Burden of disease: psoriasis and psoriatic arthritis. Am J Clin Dermatol 14(5):377-388

4. Taylor W, Gladman D, Helliwell P, Marchesoni A, Mease P, Mielants H (2006) Classification criteria for psoriatic arthritis: development of new criteria from a large international study. Arthritis Rheum 54(8):2665-2673

5. Healy PJ, Groves C, Chandramohan M, Helliwell PS (2008) MRI changes in psoriatic dactylitis - extent of pathology, relationship to tenderness and correlation with clinical indices. Rheumatology (Oxford) 47(1):92-95

6. McGonagle D, Tan AL, Benjamin M (2008) The biomechanical link between skin and joint disease in psoriasis and psoriatic arthritis: what every dermatologist needs to know. Ann Rheum Dis 67(1):1-4

7. CHANDRAN V (2009) Epidemiology of psoriatic arthritis. J Rheumatol 36(2):213-215

8. Coates LC (2010) Improving the outcome of psoriatic arthritis. University of Leeds, Unpublished. http://etheses.whiterose.ac.uk/1425

9. Rich P, Griffiths CE, Reich K, Nestle FO, Scher RK, Li S et al (2008) Baseline nail disease in patients with moderate to severe psoriasis and response to treatment with infliximab during 1 year. J Am Acad Dermatol 58(2):224-231

10. Van der Leeden M, Steultjens M, Dekker J, Prins A, Dekker J (2006) Forefoot joint damage, pain and disability in rheumatoid arthritis patients with foot complaints: the role of plantar pressure and gait characteristics. Rheumatology 45(4):465-469

11. Hyslop E, Woodburn J, McInnes IB, Semple R, Newcombe L, Hendry G et al (2010) A reliability study of biomechanical foot function in psoriatic arthritis based on a novel multi-segmented foot model. Gait Posture 32(4):619-626. doi:10.1016/j.gaitpost.2010. 09.004

12. Jacob H (2001) Forces acting in the forefoot during normal gaitan estimate. Clin Biomech 16(9):783-792

13. Chao CY, Zheng Y-P, Huang Y-P, Cheing GL (2010) Biomechanical properties of the forefoot plantar soft tissue as measured by an optical coherence tomography-based air-jet indentation system and tissue ultrasound palpation system. Clin Biomech 25(6):594-600

14. Turner DE, Hyslop E, Barn R, McInnes IB, Steultjens MP, Woodburn J (2013) Metatarsophalangeal joint pain in psoriatic arthritis: a cross-sectional study. Rheumatology ket435

15. Woodburn J, Helliwell P (1996) Relation between heel position and the distribution of forefoot plantar pressures and skin callosities in rheumatoid arthritis. Ann Rheum Dis 55(11):806-810

16. Pai S, Ledoux WR (2012) The shear mechanical properties of diabetic and non-diabetic plantar soft tissue. J Biomech 45(2):364-370

17. Helliwell P, Reay N, Gilworth G, Redmond A, Slade A, Tennant A, Woodburn J (2005) Development of a foot impact scale for rheumatoid arthritis. Arthritis Care Res 53(3):418-422

18. Quaney B, Meyer K, Cornwall MW, McPoil TG (1995) A comparison of the dynamic pedobarograph and EMED systems for measuring dynamic foot pressures. Foot Ankle Int 16(9):562-566

19. Alcacer-Pitarch B, Buch MH, Gray J, Denton CP, Herrick A, Navarro-Coy N et al (2012) Pressure and pain in systemic sclerosis/scleroderma — an evaluation of a simple intervention (PISCES): randomised controlled trial protocol. BMC Musculoskelet Disord 13(1):11

20. Julious SA (2005) Sample size of 12 per group rule of thumb for a pilot study. Pharm Stat 4(4):287-291 